Seligman, M. E. P. On the generality of the laws of learning. Psychological Review, 1970, 77, 406-418.

Van Bergeijk, W. A. Anticipatory feeding behavior in the bullfrog (Rana catesbeiana). Animal Behaviour, 1967, 15, 231-238.

Yaremko, R. M., Boice, R., \& Thompson, R. W. Classical and avoidance conditioning of the nictitating membrane in frogs (Rana pipiens) and toads (Bufo americanus). Psychonomic Science, 1969, 16, 162-164.

(Received for publication February 7, 1974.)

\title{
Context effects in speeded comprehension and recall of sentences*
}

\author{
THEODORE J. DOLL and ROBERT H. LAPINSKI \\ State University of New York at Stony Brook, Stony Brook, New York 11790
}

\begin{abstract}
Effects of four types of context on sentence processing time and recall are examined. The results are consistent with Bransford and Johnson's $(1972,1973)$ view that thematic or referential contexts facilitate comprehension by helping $S$ to gain access to relevant prior knowledge. The results also suggest that context can speed sentence processing without influencing the semantic interpretation of the input.
\end{abstract}

The present study tests some predictions concerning effects of various context conditions on sentence comprehension time and recall. Bransford and Johnson $(1972,1973)$ have suggested that thematic or referential contexts facilitate comprehension by providing cues which help $S$ to infer an acceptable interpretation of the input or a suitable organization of his prior knowledge. This view suggests that appropriate referential contexts should generally enable $\mathrm{S}$ to comprehend more quickly than in the absence of context, as well as produce greater comprehension and recall. This view also suggests that it may be possible to manipulate comprehension time by varying the amount of inferential activity required to go from the context to an acceptable interpretation of the input. Thus, contexts which only indirectly specify an appropriate theme or referential setting for the material should produce somewhat longer comprehension time than appropriate context, but should also facilitate recall relative to a neutral or no-context condition.

On the other hand, a context which is related to the

*This research was supported in part by a grant from the Joint Awards Committee/University Awards Committee of the State University of New York. material in a way which is inconsistent with any acceptable interpretation of it may mislead $\mathrm{S}$ into making inappropriate inferences. Such contexts should therefore produce longer comprehension time and should hinder comprehension and recall relative to the neutral condition. Finally, it should be possible to give $\mathrm{S}$ a head start on processing (cf. Dooling, 1972) without affecting the extent of comprehension. Thus a context which simply duplicates part of the material without suggesting a theme or referential setting should reduce comprehension time but should not affect recall relative to the neutral condition.

\section{METHOD}

\section{Design}

Each $\mathrm{S}$ experienced all five context conditions in a mixed list design. Context-sentence pairs were presented in blocks of six. Written free recall of the preceding six sentences was required after each block. The last sentence in each block served as a buffer and was not scored.

The $\mathrm{S}$ was instructed to carefully read each sentence as it appeared and to press the response button as soon as he felt that he understood it. The recall data in the present study serve the same purpose as error data in conventional RT studies, i.e., they provide a way of setting a constant lower bound on the level of processing across conditions. 
Table 1

Mean Reaction Time and Recall as a Function of Context

\begin{tabular}{lccccc}
\hline & \multicolumn{5}{c}{ Context } \\
\cline { 2 - 6 } $\begin{array}{c}\text { Dependent } \\
\text { Measure }\end{array}$ & $\mathrm{R}$ & $\mathrm{D}$ & $\mathrm{N}$ & $\mathrm{I}$ & $\mathrm{M}$ \\
\hline Recall* & 3.12 & 2.40 & 2.36 & 2.80 & 2.44 \\
Mean RT $\dagger$ & 2758 & 2762 & 3081 & 2907 & 2929 \\
\hline
\end{tabular}

Note $-R=$ referential, $D=$ duplicative, $N=$ neutral, $I=$ indirect , $M=$ misleading.

*Mean number of sentences recalled per $S$ out of 6.

$\dagger R T s$ are shown in milliseconds.

\section{Materials}

The 30 experimental sentences were constructed in such a way that they were consistent with the grammatical and semantic constraints of ordinary conversational English, but sufficiently vague or ambiguous so that the appropriate referential setting was not immediately obvious from the sentence itself, e.g., "The crowd expectantly waited for the steam."

Referential contexts directly suggested an event or object to which the setence might plausibly refer, e.g., "geyser." Indirect contexts were constructed so that they would help the $O$ infer the same event or object when given in conjunction with the sentence, but did not themselves strongly suggest the referent, e.g., "national park." Misleading contexts were associated with a word or phrase in the sentence in a manner which was inappropriate to the sentence's most obvious interpretation, e.g., "furnace." Duplicative contexts were the subject or verb of the corresponding sentence, and neutral contexts always consisted of the word ready.

\section{Procedure}

Each $\mathrm{S}$ was assigned to one of five stimulus sequences. Each experimental sentence appeared once in each sequence and was preceded by a different type of context on each occasion. Experimental sentences and context conditions were balanced as nearly as possible over sequences for block number and position within blocks.

The exposure time was $3 \mathrm{sec}$ for contexts and $4 \mathrm{sec}$ for sentences. There was a 2 -sec delay between the context and sentence, and the intertrial interval was $8 \mathrm{sec}$. Two minutes were allowed for recall after each block.

\section{Apparatus}

The stimuli were typewritten and presented via slides in a dimly illuminated room. Sentences always appeared entirely on one line. The visual angle subtended by the stimuli was comparable to that in normal reading. Events were controlled and RTs measured to the nearest millisecond by a PDP-8/L computer system.

\section{Subjects}

The Ss were 25 male and female undergraduates at the State University of New York at Stony Brook, for whom participation in the experiment counted as credit toward a course requirement. Five Ss were run on each stimulus sequence.

\section{RESULTS}

Recalled sentences were each scored by two independent raters. Responses were considered correct as long as they contained only minor changes such as reordering of phrases, changes of tense, and substitution of pronouns for proper names. There were seven discrepancies between the raters which were easily resolved in conference.
Both recall and RT data were analyzed along two dimensions, in one case using Ss as a random factor and in the other case using sentences. In the comparisons discussed below the first figures are for the analysis across Ss and second are for the analysis across sentences.

The results are shown in Table 1. Looking first at RT data, it is evident that both referential and duplicative contexts produced large reductions in relation to the neutral condition. For referential vs neutral, $F(1,24)=$ $31.6, \mathrm{p}<.001 ; \mathrm{F}(1,29)=22.8, \mathrm{p}<.001$. For duplicative vs neutral, $F(1,24)=12.7, p<.01 ; F(1,29)=$ $13.82, \mathrm{p}<.001$.

Indirect contexts produced RT intermediate between those for the referential and neutral conditions. Comparisons in both directions were significant: (a) indirect vs referential yielded $F(1,24)=6.72$, $\mathrm{p}<.05 ; \mathrm{F}(1,29)=5.30, \mathrm{p}<.05$, and (b) indirect vs neutral, $F(1,24)=5.25, p<.05 ; F(1,29)=4.47$, $\mathrm{p}<.05$.

Contrary to the prediction, RT for misleading contexts was faster than that for neutral contexts. The difference was significant across sentences but not across Ss $[F(1,24)=3.46, .05<p<.10 ; F(1,29)=4.95$, $\mathrm{p}<.05)]$.

Recall in the referential condition was significantly better than that for the neutral condition $[\mathrm{F}(1,24)=$ $4.54, \mathrm{p}<.05 ; \mathrm{F}(1,29)=5.73, \mathrm{p}<.05)]$. Neutral, duplicative, and misleading contexts all produced about the same level of recall. Indirect contexts produced recall slightly but not not significantly better than the neutral condition $[\mathrm{F}(1,24)=1.48, \mathrm{p}>.05 ; \mathrm{F}(1,29)=$ $1.92, \mathrm{p}>.05]$

To check on possible distortions of RT by differences in the level of processing, RTs were compiled for correctly recalled sentences only. Since some Ss and sentences had very few correct responses in some conditions, unweighted means of raw RTs in each condition were computed. The results are shown in Table 2. With the exception of the duplicative condition, mean RTs were on the order of $100 \mathrm{msec}$ lower than those for all responses. Even though mean RT for duplicative contexts increased, it was still considerably shorter than that for the neutral condition.

\section{DISCUSSION}

In the present study, thematic or referential contexts reduced

Table 2

Reaction Time for Correctly Recalled Sentences Only

\begin{tabular}{lccccc}
\hline & \multicolumn{5}{c}{ Context } \\
\cline { 2 - 6 } Measure & $\mathrm{R}$ & $\mathrm{D}$ & $\mathrm{N}$ & $\mathrm{I}$ & $\mathrm{M}$ \\
\hline Mean & $2670^{*}$ & 2870 & 2951 & 2780 & 2842 \\
SE & 60.4 & 66.1 & 78.1 & 66.2 & 81.5 \\
\hline
\end{tabular}

Note $-R=$ referential, $D=$ duplicative, $N=$ neutral, $I=$ indirect , $M=$ misleading.

*Data are shown in milliseconds. 
sentence processing $\mathrm{RT}$ and also increased sentence recall relative to a neutral context condition. Furthermore, contexts which were indirectly appropriate to the same themes or referential settings produced a smaller but significant reduction in RT and also tended to facilitate recall. These findings are consistent with Bransford and Johnson's $(1972,1973)$ interpretation that such contexts facilitate recall by helping $S$ to find an acceptable interpretation of the input or suitable organization of his prior knowledge. The present results therefore provide additional evidence against the view (cf. Carroll, 1972; Dooling, 1972; Katz \& Postal, 1964) that sentences are encoded or their meanings realized without access to nonlinguistic or "world" knowledge. Dooling's (1972) view is succinctly illustrated by his statement that "comprehending a sentence in context is a more complex task than comprehending a sentence in isolation." On the contrary; the present results suggest that less processing is of ten required to comprehend a sentence in context than in isolation.

In the present study, however, RT was also reduced by contexts which simply duplicated a part of the sentence to be comprehended without suggesting a theme or referential setting. As expected, such contexts did not facilitate recall. These findings suggest that context may play more than one role in comprehension, i.e., contextual information can speed sentence processing without influencing the semantic interpretation of the sentence.

The finding that misleading contexts speeded rather than slowed RT suggests that Ss may have been constructing bizzare or unexpected interpretations. The presence of referential and indirect contexts in the list may have encouraged such activity.

\section{APPENDIX}

Referential, indirect, duplicative, and misleading contexts appear from left to right under each sentence.

1. The streak blocked the light.

Window. Ammonia. Streak. Feather.

2. The man shuddered at the clap.

Thunder. Dark cloud. : Shuddered. Wind chill.

3. John could see his face in the body.

New car. Showroom. Could see. Cell tissue.

4. The sheet provided the power.

Raft. Shipwreck. Sheet. Four poster.

5. The block drew many cheers.

Football. Sunday afternoon. Drew. Toy.

6. The crowd expectantly waited for the steam.

Geyser. National park. Crowd. Furnace.

7. He could not see because one blade was broken.

Windshield. Rainstorm. Was broken. Jack-knife.

8. The pull on the line was caused by a tire.

Fishing. Off the pier. Pull. Blowout.

9. He kicked twice but got no change.

Vending machine. Soft drink. Kicked. Burlesque.

10. The bird was too small for the family.

Thanksgiving dinner. Pumpkin pie. Bird. Nest.

11. He feared falling through because of the warm weather. Thin ice. Winter sport. Feared. Skydiver.

12. The bell rang while he was on the canvas. Boxing match. Sports arena. Bell. Schoolroom.
13. He quickly ou tlined the platform. Politician. Convention. Outlined. Teacher.

14. The flakes coagulated in the boiling water. Oatmeal. Breakfast. Flakes. Snow.

15. He sliced past a group of trees. Golf. Club. Sliced. Baloney.

16. The eye is comparatively calm. Hurricane. Foul weather. Eye. Guide dog.

17. Mary stepped from the window into the boat. Flood. Broken dam. Stepped. Fish.

18. A circular pattern of stars was suggested. Flag. American Revolution. Pattern. General.

19. The hands moved slowly over the numbers. Clock. Chimes. Hands. Mathematics.

20. As the water hit the couch, there was a sigh of relief. Fire. Cigarette. Water. Waiting room.

21. From inside the crown he looked on the harbor. Statue of Liberty. Monument. Looked. British coin.

22. Martha clutched the chair and refused to look down. Ski lift. Winter sport. Clutched. Furniture.

23. The artist worked without a net. Trapeze. Circus. Artist. Portrait.

24. Despite all efforts the spiral continued. Inflation. Government control. Continued. Whirlpool.

25. His palms sweated at the buzzing. Dentist's drill. Tooth decay. Palms. Heat wave.

26. The float turned the corner. Parade. Holiday. Float. Rough water.

27. He turned the key and pressed with his foot. Automobile. Motor. Turned. Wrestling.

28. With the last tick the building was leveled. Time bomb. Saboteur. Building. Metronome.

29. The gates slowly enclosed the ship. Canal lock. Isthmus. Enclosed. Picket fence.

30. The rusty handle brought up water. Pump. Campground. Handle. Suitcase.

\section{REFERENCES}

Bransford, J. D., \& Johnson, M. K. Contextual prerequisites for understanding: Some investigations of comprehension and recall. Journal of Verbal Learning \& Verbal Behavior, 1972, 11, 717-726.

Bransford, J, D, \& Johnson, M, K . Considerations of some problems of comprehension. In W. G. Chase (Ed.), Visual information processing. New York: Academic Press, 1973.

Carroll, J. B. Defining language comprehension: Some speculations. In J. B. Carroll and A. O. Freedle (Eds.), Language comprehension and the acquisition of knowledge. Washington, D.C: Winston, 1972 .

Dooling, J. D. Some context effects in the speeded comprehension of sentences. Journal of Experimental Psychology, 1972, 93, 56-62.

Katz, J. J., \& Postal, P. M. An integrated theory of linguistic descriptions. Cambridge, Massachusetts: M.I.T. Press, 1964. 